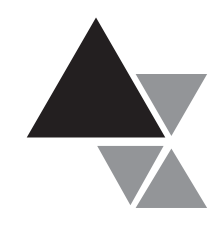

\title{
PRÓPOLIS E SEGURANÇA ALIMENTAR
}

\author{
Risia Cristina Coelho Lacerda, Ana Paula Tiveron², Severino Matias de Alencar ${ }^{3}$
}

A própolis é um material resinoso coletado de plantas e cascas de árvores pelas abelhas Apis mellifera, é dotada de substâncias biologicamente ativas com propriedades antioxidantes, anti-inflamatória, antitumoral e antimicrobiana. O objetivo desse trabalho consistiu em avaliar a segurança alimentar do uso da própolis na prevenção e no tratamento de doenças. O levantamento da literatura estudada foi feito de modo a abordar a relevância das propriedades terapêuticas da própolis através dos vários estudos científicos bem como possíveis efeitos colaterais pelo uso indiscriminado, podendo resultar em reações alérgicas graves. Desta forma, se faz necessário a discussão do tema por corroborar com a saúde pública.

Palavras-chave: própolis, antioxidante, consumo seguro.

\section{PROPOLIS, FOOD SAFETY AND SECURITY}

Propolis, a resinous substance collected from the buds and bark of various plants and trees collected by Apis mellifera bees, is composed by many biological substances. It is claimed to have antioxidant, antiinflammatory, antitumor, and antimicrobial properties. The aim of this review was to evaluate the food safety of propolis in disease prevention as well as for treating illnesses. In this paper, we not only report relevant findings from scientific literatures about the therapeutic applications of propolis but also possible side effects by its improper use whereas leading to allergic reaction. By the same token, the discussion about this theme corroborates with public health.

Key-words: propolis, antioxidant, safe consumption.

\footnotetext{
${ }^{1}$ Mestranda do Programa de Pós-graduação em Ciência e Tecnologia de Alimentos, Depto. de Agroindústria, Alimentos e Nutrição - Escola Superior de Agricultura Luiz de Queiroz (ESALQ), Universidade de São Paulo (USP), Piracicaba, SP. Correspondência: Av. Pádua Dias, 11, CEP 13418-900, Piracicaba, SP. E-mail: rilacerda@usp.br.

${ }^{2}$ Doutoranda do Programa de Pós-graduação em Ciência e Tecnologia de Alimentos, Depto. de Agroindústria, Alimentos e Nutrição, ESALQ, USP.

${ }^{3}$ Prof. Dr., Depto. de Agroindústria, Alimentos e Nutrição, ESALQ, USP.
} 


\section{INTRODUÇÃO}

Civilizações antigas com as suas terapias milenares conheceram e utilizaram os produtos das abelhas como valiosos recursos em suas práticas medicinas. O histórico das medicinas das civilizações chinesa, tibetana, egípcia e também a greco-romana é muito rico, contendo em seus registros, datados de longo tempo, centenas de receitas, incluindo entre os principais ingredientes, o mel, própolis, larvas de abelhas e eventualmente as próprias abelhas para curar ou prevenir enfermidades ${ }^{[1]}$.

A própolis é um material resinoso coletado de diversas partes de plantas, por abelhas (Apis mellifera), as quais enriquecem a mesma com suas secreções salivares e enzimáticas. As abelhas usam essa resina para vedar suas colmeias, protegendo-as assim, de insetos e microorganismos invasores [2]. Mais recentemente, a própolis tem sido utilizada no tratamento de várias doenças por parcela da população de países como Japão, Brasil, Estados Unidos e Europa, bem como, tem sido frequente a utilização como ingrediente em produtos cosméticos ${ }^{[3]}$. Estudos relatam que a própolis tem uma grande variedade de atividades biológicas tais como a antimicrobiana, antiinflamatória, antioxidante e antitumoral ${ }^{[4-6]}$. A própolis também contém na sua composição química uma grande variedade de compostos como os terpenóides, esteróides, flavonóides, ácidos fenólicos e seus ésteres [7]. Essa variabilidade ocorre de acordo com a flora da área geográfica ${ }^{[8]}$. Por esta razão, a própolis de regiões não exploradas atraem a atenção de cientistas, os quais estão em busca de novas moléculas bioativas.

Tendo em vista a dimensão das atividades biológicas da própolis e sua importância, julgou-se relevante a realização dessa revisão com o objetivo de descrever a segurança alimentar do uso da própolis na prevenção e no tratamento de doenças.

\section{MÉTODOS}

O método adotado para a pesquisa compreende uma revisão bibliográfica, baseada no levantamento de artigos científicos. Também serão descritos, de forma analítica, a legislação brasileira sobre as características que a própolis deve apresentar para sua segurança alimentar.

\section{CARACTERÍSTICAS DA PRÓPOLIS E SEU IMPACTO NA SAÚDE}

A própolis é uma resina coletada por abelhas da espécie Apis mellifera de diversas partes das plantas como brotos, botões florais e exudados resinosos ${ }^{[9]}$, e vem se destacando tanto pelas suas propriedades biológicas, como atividade antimicrobiana, antiinflamatória, cicatrizante, anestésica, antitripanossomal ${ }^{[9-17]}$, anticariogênica ${ }^{[18-20]}$, antiviral, anticarcinogênica, antioxidante ${ }^{[16,21-24]}$ e fitotóxica ${ }^{[25]}$. Nos últimos anos, a própolis tem sido utilizada em creme dental, solução de bochecho, devido as suas propriedades anticárie, antimicrobiana e antioxidante ${ }^{[2]}$. Nascimento et al. ${ }^{\text {[27] }}$ verificaram que extratos de própolis vermelha e verde promoveram uma intensificação no fator de proteção solar quando incorporados nas formulações fotoprotetoras. Os melhores resultados foram obtidos com o extrato etanólico da própolis verde.

$\mathrm{Na}$ Europa, América do Norte e Oeste da Ásia a fonte de própolis é o exsudado do botão de álamo (Populus sp.), sendo que somente um único tipo de própolis é encontrado ${ }^{[28,29]}$. Entretanto, na América do Sul, a espécie vegetal do gênero Populus sp. não é nativa, existindo uma grande diversidade vegetal para a retirada de resina, condição que dificulta inclusive a correlação da própolis com a fonte produtora. A dependência geográfica e vegetal, fatores preponderantes da própolis é exemplificada nos trabalhos da própolis da América do Sul, Europa, China, Canadá e Espanha ${ }^{[30-35]}$. A própolis taiwanesa, por exemplo, é rica em ácidos fenólicos e flavonóides, apresentando alta atividade antioxidante [21]. Entretanto, a própolis verde, que é encontrada somente no Brasil, mais precisamente na região de Minas Gerais, não apresenta flavonóides como composto principal, mas, benzofurano, que possui propriedades de alta atividade citotóxica ${ }^{[36]}$.

Análises de própolis oriundas do Brasil e da Venezuela confirmaram a presença de compostos incomuns, além dos flavonóides, em relação aos componentes das própolis europeias e dos demais

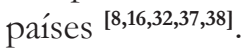

A própolis brasileira foi classificada em 12 grupos, sendo que aqueles que apresentaram melhor atividade antimicrobiana foram os grupos dos respectivos estados: 3 (RS); 6 (BA); 12 (MG) ${ }^{[39]}$. Os autores 
identificaram diferenças qualitativas e quantitativas na composição química destes grupos, adotando técnicas de cromatografia líquida de alta eficiência e cromatografia gasosa com espectrometria de massas. As própolis do grupo 3 mostraram a presença do éster do ácido dimetil dialil caféico, o qual é um composto altamente alergênico e comumente encontrado em própolis de climas temperados. Integrantes do grupo 6 apresentaram uma composição química distinta dos demais grupos, principalmente pela ausência de flavonóides. Entretanto, este foi o grupo que apresentou as maiores atividades contra os microrganismos Streptococcus mutans e Staphylococcus aureus coagulase positiva.

A própolis verde, encontrada no Brasil na região de Minas Gerais é rica em terpenóides e derivados prenilados do ácido cumárico ${ }^{[3]}$.

Pioneiramente, Alencar et al. ${ }^{[16]}$ e Silva et al. ${ }^{[40]}$ estudaram a própolis vermelha produzida na região de mangue do Estado de Alagoas, baseandose principalmente na sua composição química rica em isoflavonóides e alta atividade antimicrobiana e classificaram como um novo tipo de própolis brasileira (13ํำ tipo). Com base em estudos fitoquímicos, esses autores identificaram a origem botânica desta própolis como sendo a espécie vegetal Dalbergia ecastophyllum (L).

A própolis também está sendo adicionada em alimentos e bebidas com a finalidade de melhorar a saúde e prevenir doenças, como inflamações, diabetes, doenças cardíacas e cânceres ${ }^{[2,41,42]}$. Estudos conduzidos por Bernardi ${ }^{[43]}$ avaliaram a funcionalidade da própolis livre e microencapsulada em salame tipo italiano e revelaram efeito antioxidante no produto. Também, Queiroz et al. [44] analisaram o comportamento da oxidação da carne de pescado salgado tratados com própolis e obtiveram efeitos positivos relacionados ao efeito antioxidante. Assim sendo, estudos corroboram com a busca na substituição de antioxidantes sintéticos, como o BHA (butil-hidroxianisol), o BHT (butilhidroxitolueno) e o TBHQ (terc-butilhidroquiniona), amplamente utilizados pela indústria de alimentos, por antioxidantes naturais, como os compostos fenólicos, e sua aplicabilidade em alimentos. Em relação ao possível sabor agregado pela própolis, houve variação entre as amostras com o passar do tempo, dependendo do tratamento aplicado (própolis livre ou diferentes formas de microencapsulação), havendo mascaração do sabor. Borges et al. ${ }^{[45]}$, ao incorporar extrato hidroalcoólico de própolis verde em linguiça suína frescal defumada, verificaram ausência de alterações sensoriais, para todas as concentrações testadas e inibição do crescimento microbiano. Tendo em vista os resultados positivos, os autores sugerem que os extratos hidroalcoólicos da própolis testada podem ser utilizados como conservantes, além de proporcionarem um enriquecimento devido aos compostos bioativos presentes.

\section{ATIVIDADE ANTIOXIDANTE E SEUS BENEFÍCIOS}

Mais recentemente, uma das propriedades mais exploradas da própolis tem sido a atividade antioxidante. Pesquisas destacam a atividade antioxidante e a composição química da própolis, nesse sentido, Oldoni ${ }^{[46]}$, concluiu que a própolis vermelha apresenta maior atividade antioxidante quando comparada a produtos sintéticos comercialmente usados como antioxidantes. Ao realizar o fracionamento da própolis vermelha, a autora acima constatou que a inibição da peroxidação lipídica e sequestros de radicais livres se revelaram mais eficazes com a própolis vermelha. Tais resultados apresentam grande relevância, uma vez que os antioxidantes mais utilizados pela indústria de alimentos, como o BHA, o BHT e o TBHQ, têm despertado preocupação quanto as suas doses de segurança e toxicidade ${ }^{[47]}$. Assim, estudos sobre compostos fenólicos como antioxidantes naturais se tornam cada vez mais importantes.

Outros pesquisadores como Ahn et al. ${ }^{[48]}$ avaliaram a atividade antioxidante por meio da adoção de três diferentes métodos, em amostras de própolis chinesas. As amostras que apresentaram as melhores atividades possuíam em sua composição compostos fenólicos como ácido caféico, ácido ferúlico e o ácido caféico éster fenetil (CAPE). Estudo desenvolvido por Kumazawa et al. ${ }^{[49]}$ isolou e identificou 33 compostos em própolis uruguaia, sendo 18 flavonóides, 4 ácidos carboxílicos aromáticos e 11 ésteres de ácido fenólico, demonstrando assim, a existência da grande variabilidade da composição química encontrada na própolis proveniente de lugares diferentes. Da mesma forma, Gardana et al. ${ }^{[50]}$ descreveram que a própolis chinesa, argentina e europeia possuem ácidos fenólicos e flavonóides, como crisina e galangina, que apresentam atividade antioxidante elevada. Fernandez et al. ${ }^{[35]}$ analisaram a presença de isoflavonóides 
em sete variedades de própolis vermelha cubana, enquanto que Isla et al. ${ }^{[51]}$ e Bonvehi \& Coll [33] afirmam que os flavonóides são os antioxidantes mais abundantes e efetivos em própolis. Além disso, Mirzoeva et al. ${ }^{[52]}$ encontraram relação direta entre a presença do ácido caféico e quercetina em extratos etanólicos de própolis e atividade antitumoral e antimicrobiana. Pesquisas realizadas por Xu et al. ${ }^{[33]}$ ressaltaram que, os constituintes da própolis podem apresentar efeitos sinergéticos, conferindo às mesmas, diferentes propriedades farmacológicas.

O estudo realizado por Inokuchi et al. [3] comprovou a eficácia da própolis verde na proteção da retina em relação à oxidação. Transtornos oculares como glaucoma e neuropatias oculares causados pelo diabetes ou pela oclusão dos vasos oculares são decorrentes do stress oxidativo. Da mesma forma, dados clínicos e experimentais sugerem que danos neurológicos encontrados na isquemia cerebral são parcialmente induzidos por radicais livres e pela peroxidação lipídica. Espécies reativas de oxigênio como $\mathrm{H}_{2} \mathrm{O}_{2}$, óxido nítrico (NO), ânion superóxido $\left(\mathrm{O}_{2} \cdot-\right)$ e radical hidroxila $(\mathrm{OH})$ - quando produzidas em excesso induzem a morte de vários tipos de células, notadamente os neurônios. O estudo de Shimazawa et al. ${ }^{[54]}$ demonstrou que essa atividade pode ser inibida pela própolis verde, em parte, pela sua ação antioxidante. Bankova ${ }^{[5]}$ relatou que estudos desenvolvidos por Chen et al. ${ }^{[21]}$ isolaram dois novos compostos da própolis taiwanesa com ação citotóxica, sendo eles as prenilflavonas. Em 2004, Chen et al. [7] encontraram resultados positivos em seu estudo. Nota-se que a própolis taiwanesa analisada pelos autores, apresentou caráter indutório do processo apoptótico nas células do melanoma humano.

\section{LEGISLAÇÃO E SEGURANÇA ALIMENTAR}

A própolis sendo um produto natural, de características físicas resinosas e composição variável, coletada de várias espécies vegetais e que sofre adição de secreções da abelha, é classificada como opoterápico. As condições mínimas para o seu registro estão definidas na RDC no 132/2003 [56].

Entretanto, as condições mínimas de qualidade abordadas pela Agência Nacional de Vigilância Sanitária (ANVISA) preconizam análise das características sensoriais, como aspecto, cor e odor; requisitos físico-químicos como perda por dessecação, teor de cinzas totais, cinzas insolúveis em ácido clorídrico, densidade, viscosidade e pH; determinação do teor alcoólico (quando for o caso); atividade antioxidante; marcadores qualitativamente e quantitativamente; bem como teor de fenóis totais, teor de flavonóides, teor de compostos voláteis e teor de ceras ${ }^{[57]}$. Além disso, se faz necessário pesquisar e identificar contaminantes e patógenos, incluindo esporos de Paenibacillus larvae, coliformes, fungos e leveduras, aditivos, metais pesados, resíduo de pesticidas, determinação de material estranho e um laudo de análise do fornecedor com descrição dos processos de produção e coleta da própolis, constando todos os itens descritos acima ${ }^{58]}$.

Para a comprovação de eficácia e segurança, a ANVISA não estabelece a exigência para produto anti-inflamatório, antisséptico e cicatrizante de uso tópico, da realização de estudos de comprovação de eficácia. Todavia, para outras indicações não derivadas de uso tradicional e para associações que envolvam própolis e extratos vegetais ativos, deve ser apresentada pelo menos, uma comprovação clínica (Fase III) do efeito terapêutico e da segurança de uso para a própolis específica que é utilizada no produto ou na associação. A comprovação da eficácia e da segurança de uso também pode ser apresentada por meio de literatura científica indexada em bases de dados, que tiveram por referência, estudos realizados com a própolis específica como objeto, do produto a ser registrado. Contudo, se faz necessário, a apresentação de no mínimo oito estudos, englobando ensaios clínicos e de segurança de uso do produto ${ }^{[57]}$.

Nos últimos anos, no comércio mundial de alimentos, o extrato de própolis temi um alto valor agregado, que pode ser justificado em parte pelo interesse pela própolis brasileira. A produção nacional é a terceira maior produção no ranking mundial e responde por $80 \%$ da demanda do mercado japonês. Esta conquista tem sido motivada pelo fato da própolis brasileira apresentar menor teor de metais pesados ${ }^{[38]}$. De acordo com Sawaya et al. ${ }^{[59]}$, a legislação brasileira permite 35\% (peso/peso) de componentes extraídos por etanol e um máximo de 5\% (peso/peso) de cinza, $25 \%$ (peso/peso) de cera. 
Devido às importantes características da própolis e ampla produção no Brasil, torna-se necessário que maior número de políticas públicas de incentivo aos produtores sejam realizadas, como o Programa Viva o Mangue Vivo, criado em 2009 pelo Serviço Brasileiro de Apoio às Micro e Pequenas Empresas (SEBRAE), que já beneficiou mais de 350 apicultores em 9 municípios no Estado da Paraíba, grande produtor de própolis vermelha. Com o apoio do governo é possível garantir a renda de diversas famílias, além de promover um destaque internacional cada vez maior do Brasil no que diz respeito a produção de própolis.

No que diz respeito à questão alimentar, ultimamente a própolis vem sendo empregada em várias formulações. De acordo com o Codex Alimentarius ${ }^{[60]}$, alimento é qualquer substância, tanto processada, semi-processada ou crua, utilizada na intenção de consumo humano, incluindo bebidas, gomas de mascar e qualquer substância que seja usada em manufatura, preparação ou tratamento de alimentos, porém não inclui cosméticos, tabaco ou substâncias usadas somente como drogas. Alimento seguro é aquele inócuo à saúde humana, ou seja, livre de perigos, que neste contexto pode ser um agente biológico, químico ou físico, ou condição do alimento com um potencial de causar efeito adverso à saúde.

Pesquisas sobre a aplicação de própolis em alimentos se destacam cada vez mais e tendem a se tornarem cada vez mais frequentes frente ao amplo cenário de propriedades biológicas que este produto apresenta. A própolis apresenta na sua composição vitaminas e minerais como alumínio, cálcio, estrôncio, ferro, cobre e manganês ${ }^{[9,61]}$ e pequenas quantidades de vitaminas $\mathrm{B}_{1}, \mathrm{~B}_{2}, \mathrm{~B}_{6}, \mathrm{C}$ e E ${ }^{[9]}$. O Ministério da Agricultura, Pecuária e Abastecimento (MAPA) considera a própolis como alimento de origem animal, não podendo este ser comercializado com indicação terapêutica.

\section{RISCOS DO USO DA PRÓPOLIS}

Por ser um produto natural rico em terpenos, ácido cinâmico, ácido caféico e seus derivados, flavonóides e aminoácidos ${ }^{[61]}$, a própolis vem sendo incorporada em preparações biocosméticas, creme dental, xarope, enxágue bucal e soluções orais ${ }^{[8,26,59]}$. Entretanto, seu uso deve ser cauteloso, devido à possibilidade de reações adversas como, por exemplo, reações alérgicas, estomatite, edema labial, eczema perioral e dispneia ${ }^{[62]}$. Cho et al. ${ }^{[62]}$ relatam que, recentemente, o número de registros de casos de dermatite de contato tem aumentado paralelamente ao crescimento do uso da própolis. Os mesmos autores descrevem o primeiro caso de dermatite de contato sistêmica por consumo de própolis em uma mulher de 36 anos. A paciente apresentou prurido severo múltiplo, pápulas eritematosas e edema de face, pescoço, braços, abdômen e coxas após a ingestão de própolis por algumas semanas, obtida de um apicultor. Biópsia do tecido foi requerida pela equipe médica, sendo que os resultados histopatológicos revelaram espongiose, edema de derme papilar com vasodilatação e infiltração perivascular de eosinófilos e linfócitos concluindo, no diagnóstico, dermatite de contato. A paciente foi tratada com corticóides e antihistamínicos. Após quatro semanas de tratamento, a mesma foi submetida ao teste de alergia com adesivos de vaselina contendo própolis a 10\%. Como resultado, a paciente apresentou reação alérgica extrema.

Teraki \& Shiohara ${ }^{[63]}$ relataram reação adversa em um paciente que utilizou uma loção contendo própolis, para tratamento de ferimento abaixo do nariz. Foram descartadas infecções por fungos e bactérias e o diagnóstico final foi dermatite de contato granulomatoso, acompanhado de linfoadenopatia.

Outro fator importante a ser considerado é a possível presença de metais pesados em determinados tipos de própolis. Conti \& Botré ${ }^{[64]}$ analisaram mel, própolis, pólen e cera como indicadores biológicos de poluição ambiental, através dos teores de metais pesados (cádmio, cromo e chumbo). Metais pesados são tóxicos e competem com os metais naturais presentes na própolis, com possibilidade de causar sérios danos à saúde humana e animal.

\section{CONSIDERAÇÕES FINAIS}

A própolis é uma substância natural carreadora de múltiplas atividades biológicas benéficas no tratamento e prevenção de doenças decorrente de seu efeito antioxidante. Além do mais, é também um ótimo substituto dos antioxidantes artificiais usados na conservação de alimentos. Devido sua ação antimicrobiana, a própolis é usada em cremes dentais, enxágue bucal bem como em cosméticos. Todavia, profissionais da saúde devem ser cautelosos na indicação do mesmo, pois a própolis pode sensibilizar o sistema imunológico. Os desafios das pesquisas 
envolvendo própolis compreendem o tipo de solvente usado, isenção de metais pesados e agrotóxicos. Os resultados das mesmas poderão subsidiar os setores da saúde, tecnologia e produção de alimentos que estão envolvidos com o alcance da segurança alimentar.

\section{REFERÊNCIAS}

1. Schneidewind EM, Kala H, Linzer B, Metzner J. Knowledge of constituents of propolis. Pharmazie. 1975;30(12):803.

2. Daugsch A, Moraes C, Fort P, Park Y. Brazilian Red Propolis Chemical composition and botanical origin. Evid Based Complement Alternat Med. 2008;5(4):435-41.

3. Inokuchi Y, Shimazawa M, Nakajima Y, Suemori S, Mishima S, Hara H. Brazilian green propolis protects against Retinal Damage In vitro and In vivo. Evid Based Complement Alternat Med. 2006;3(1):71-7.

4. Grange J M \& Davey R W. Antibacterial properties of propolis (bee glue). J R Soc Med. 1990;83(3):159-60.

5. Najafi M, Vahedy F, Seyyedin M, Jomehzadeh H R, Bozary $K$. Effect of the water extracts of propolis on stimulation and inhibition of different cells. Cytotechnology . 2007;54(1):49-56.

6. Missima F, Sforcin JM. Green Brazilian propolis action on macrophages and lymphoid organs of chronically stressed mice. Evid Based Complement Alternat Med. 2008;5(1):71-75.

7. Chen C, Weng M, Wu C, Lin J.Comparison of Radical Scavenging Activity, Cytotoxic Effects and Apoptosis Induction in Human Melanoma Cells by Taiwanese Propolis from Different Sources. Evid Based Complement Alternat Med. 2004;1(2):175-185.

8. Trusheva B, Popova B, Bankova V, Simova S, Marcucci MC, Miorin PL et al. Bioactive constituents of Brazilian red própolis. Evid Based Complement Alternat Med. 2006;3(2):249-54.

9. Ghisalberti EL. Própolis: a review. Bee World. 1979;60(2):59-84.

10. Bankova V, Popov S, Marekov NL. Isopentenyl cinnamates from poplar buds and propolis. Phytochemistry. 1989;28(3):871-73.
11. Park YK, Koo MH, Ikegaki M, Cury JA, Rosalem PL, Abreu JAS. Antimicrobial activity of propolis on oral microorganisms. Curr Microbiol. 1998;36(1):24-28.

12. Kujumgiev A, Tsvetkova I, Serkedjieva Y, Bankova V, Christov R, Konig Popov S. Antibacterial, antifungal and antiviral activity of propolis of different geographic origin. J Ethnopharmacol. 1999;64(3):235-40.

13. Marcucci MC, Ferreres F, Garcia-Viguera C, Bankova VS, Castro SL, Dantas AP et al. Phenolic compounds from Brazilian propolis with pharmacological activities. J Ethnopharmacol. 2001;74(2):105-12.

14. Montpied P, Bock F, Rondouin G, Niel G, Briant L, Courseau AS et al. Caffeic acid phenethyl ester (CAPE) prevents inflammatory stress in organotypic hippocampal slice cultures. Brain Res Mol Brain Res. 2003;115(2):111-20.

15. Cunha IBDS, Salomão K, Shimizu M, Bankova VS, Custódio AR, Castro SL et al. Antitrypanosomal activity of Brazilian Propolis from Apis mellifera. Chem Pharm Bull. 2004;52(5):602-04.

16. Alencar SM, Cadorin TL, Castro ML, Ribeiro IS, CostaNeto CM, Cury JA et al. Chemical composition and biological activity of a new type of Brazilian propolis: red propolis. J Ethnopharmacol. 2007;113(2):278-83.

17. Cabral ISR, Oldoni TLC, Prado A, Bezerra RMN, Alencar $\mathrm{SM}$, Ikegaki $\mathrm{M}$ et al. Composição fenólica, atividade antibacteriana e antioxidante da própolis vermelha brasileira. Quím Nova. 2009;32(6):1523-27.

18. Koo H, Rosalem PL, Cury JA, Ambrosano GMB, Murata RM, Yatsuda R et al. Effect of a new variety of Apis mellifera propolis on mutants Streptococci. Curr Microbiol. 2000;(3):192-96.

19. Koo H, Rosalem PL, Cury J, Park Y, Bowen W. Effects of compounds found in propolis on Streptococcus mutans growth and on glucosyltransferase activity. Antimicrob Agents Chemother. 2002;46(5):1302-09.

20. Duarte S, Rosalem PL, Hayacibara MF, Cury JA, Bowen WH, Marquis RE et al. The influence of a novel propolis on mutans streptococci biofilms and caries development in rats. Arch Oral Biol. 2006;51(1):15-22. 
21. Chen CN, Wu CL, Shy HS, Lin JK. Cytotoxic Prenylflavanones from Taiwanese Propolis. J Nat Prod. 2003;66(4):503-06.

22. Aso K, Kanno SI, Tadano T, Satoh S, Ishikawa M. Inhibitory effect of propolis on the growth of human leukemia U937. Biol Pharm Bull. 2004;27(5):727-30.

23. Ishikawa M, Kanno S, Asou K, Ogino M, Tadano T, Satou S. Inhibition of growth and induction of apoptosis in human cancer cell lines by Propolis. J Pharmacol Sci. 2004;94(Supl. 1):129.

24. Li F, Awale S, Tezuka Y, Kadota S. Cytotoxic constituents from Brazilian red propolisand their structure-activity relationship. Bioorg Med Chem. 2008;16(10):5434-40.

25. Johnson KS, Eischen FA, Giannasi DE. Chemicalcompositing of North-American bee propolis and biologicalactivity towards larvae of greater wax moth (Lepidoptera, Pyralidae).J Chem Ecol. 1994;20(7):1783-91.

26. Özan F, Sümer Z, Polat Z, Er K, Özan U, Deger O. Effect of mouthrinse containing propolis on oral microorganisms and human gingival Fibroblasts. Eur J Dent. 2007;1(4):195-201.

27. Nascimento CS, Nunes LCC, Lima AAN, Júnior SG, neto PJR. Incremento do FPS em formulação de protetor solar utilizando extratos de própolis verde e vermelha. Revista Brasileira de Farmácia. 2009;90(4):334-39.

28. Markham RK, Mitchell KA, Wilkins AL, Daldy JA, Lu Y. HPLC and GC-MS identification of the major organic constituints in new Zealand propolis. Phytochemistry. 1996;42(1):205-11.

29. Wollenweber E, Buchmann SL. Feral honey bees in the Sonoran Desert: propolis sources other than poplars (Populus spp.) Z Naturforsch C. 1997;52(7-8):530-535.

30. König B. Plant sources of propolis. Bee World. 1985; 66:136-139.

31. Garcia-Viguera C, Greenway W, Whatley Fr. Composition of propolis from 2 different Spanish regions. Z Naturforsch C. 1992;47(7-8):634-37.

32. Tomas-Barberan FA, Garcia-Viguera C, Vit-Olivier P, Ferreres F, Tomas-Lorente F. Phytochemical evidence for the botanical origin of tropical propolis from Venezuela. Phytochemistry. 1993; 34(1):191-6.

33. Bonvehi JS, Coll FV. Phenolic composition of propolis from China and from South-America. Z Naturforsch C. 1994;49(11-12):712-18.

34. Park YK, Alencar SM, Aguiar CL. Botanical origin and chemical composition of Brazilian propolis. J Agric Food Chem. 2002;50(9):2502-06.

35. Fernandez MC, Cuesta-Rubio O, Perez AR, Montes de Oca Porto R, Hernandez IM, Piccinelli AL et al. GC - MS Determination of isoflavonoids in seven Cuban propolis samples. J Agric Food Chem. 2008;56(21):9927-32.

36. Salatino A, Teixeira EW, Negri G, Message D. Origin and chemical variation of Brazilian própolis. Evid Based Complement Alternat Med. 2005;2(1):33-38.

37. Marcucci, M C. Propolis: chemical composition, biological properties and therapeutic activity. Apidologie. 1995;26(1):83-99.

38. Pereira AS, Seixas FRM, Neto FRA. Própolis: 100 anos de pesquisa e suas perspectivas futuras. Quím Nova. 2002;25(2):321-26.

39. Park Y, Ikegaki M, Alencar SM, Moura FF. Evaluation of Brazilian propolis by both physicochemical methods and biological activity. Honey Bee Science. 2000;21(2):85-90.

40. Silva BB, Rosalem PL, Cury JA, Ikegaki M, Souza VC, Esteves A et al. Chemical composition and botanical origin of red propolis, a new type of Brazilian propolis. Evid Based Complement Alternat Med. 2008;3(5):313-16.

41. Burdock GA. Review of the biological properties and toxicity of bee propolis. Food Chem Toxicol. 1998;36(4):347-63.

42. Banskota AH, Tezuka Y, Kadota S. Recent progress in pharmacological research of própolis. Phytother Res. 2001;15(7):561-71.

43. Bernardi S. Funcionalidade de própolis livre e microencapsulada em salame tipo italiano [dissertação]. Piracicaba: Escola Superior de Agricultura Luiz de Queiroz, Piracicaba; 2010.127 p.

44. Queiroz MI, Badiale-Furlong E, Coelho CSP, Zílio RL, Correa AC. Avaliação do comportamento da oxidação de 
carne de pescado salgado tratado com própolis. B CEPPA. 1996;14(2):273-80.

45. Borges CHF, Almeida DA, Fragiorge EJ. Atividade antibacteriana e antifúngica de diferentes concentrações de extratos hidroalcoólicos de própolis (EHP) em linguiça frescal suína. Fazu em Revista. 2009;6:53-82.

46. Oldoni TLC. Isolamento e identificação de compostos com atividade antioxidante de uma nova variedade de própolis brasileira produzidas por abelhas da espécie $A$ pis mellifera [dissertação]. Piracicaba: Escola Superior de Agricultura Luiz de Queiroz, Universidade de São Paulo; 2007. 104 p.

47. Wanasundara UN, Shahidi F. Antioxidant and prooxidant activity of green tea extracts in marine oils. Food Chem. 1998;63(3):335-42.

48. Ahn MR, Kumazawa S, Usi Y, Nakamura J, Matsuka M, Zhu $\mathrm{F}$ et al. Antioxidant activity and constituents of propolis collected in various areas of China. Food Chem. 2007;101(4):1383-92.

49. Kumazawa S, Hayashi K, Kajiya K, Ishii T, Hamasaka T, Nakayama T. Studies of the constituents of Uruguayan propolis. J Agric Food Chem. 2002;50(17):4777-82.

50. Gardana C, Scaglianti M, Pietta P, Simonetti P. Analysis of the polyphenolic fraction of propolis from different sources by liquid chromatography-tandem mass spectrometry. J Pharm Biomed Anal. 2007;45(3):390-99.

51. Isla MI, Nieva Mi, Sampietro AR, Vattuone MA. Antioxidant activity of Argentine propolis extracts. J Ethnopharmacol. 2001;76(2):165-70.

52. Mirzoeva OK, Grishanin RN, Calder PC. Antimicrobial action of propolis and some of its components: The effects on growth, membrane potential and motility of bacteria. Microbiol Res. 1997;152(3):239-46.

53. Xu Y, Luo L, Chen B, Fu Y. Recent development of chemical components in própolis. Front Biol. 2009;4(4):385-91.

54. Shimazawa M, Chikamatsu S, Morimoto N, Mishima S, Nagai H, Hara H. Neuroprotection by Brazilian Green Propolis against In vitro and In vivo Ischemic Neuronal Damage. Evid Based Complement Alternat Med. 2005;2(2):201-207.
55. Bankova V. Recent trends and important developments in propolis research. Evid Based Complement Alternat Med. 2005;2(1):29-32.

56. Brasil. Ministério da Saúde. Agência Nacional de Vigilância Sanitária. Resolução RDC no 132, de 29 de maio de 2003. Dispõe sobre o registro de medicamentos específicos. Diário Oficial da União, Brasília, 02 out. 2003. Seção 1, p. 68.

57. Brasil. Agência Nacional de Vigilância Sanitária. Câmara Técnica de Medicamentos Fitoterápicos - CATEF. Nota Técnica sobre o registro de produtos contendo própolis [acesso em 06 nov 2011]. Disponível em: http://www. anvisa.gov.br/medicamentos/catef/propolis.htm

58. Brasil. Ministério da Agricultura e do Abastecimento. Secretaria de Defesa Agropecuária. Instrução Normativa no 3, de 19 de janeiro de 2001. Aprovar os Regulamentos Técnicos de Identidade e Qualidade de Apitoxina, Cera de Abelha, Geleia Real, Geleia Real Liofilizada, Pólen Apícola, Própolis e Extrato de Própolis, conforme consta dos Anexos desta Instrução Normativa. Diário Oficial da União, Brasília, 23 jan. 2001. Seção 1, p. 46.

59. Sawaya A, Cunha I, Marcucci M. Analytical methods applied to diverse types of Brazilian propolis. Chem Cent J. 2011;5927):1-10.

60. World Health Organization/Food and Agriculture Organization. Codex alimentarius comission. Procedural manual. Twentieth edition, Rome; 2011.

61. Wang L, Lin Y, Liang Y, Yang Y, Lee J, Yu H, Wu W, Chiang B. The effect of caffeic acid phenethyl ester on the functions of human monocyte-derived dendritic cells. BMC Immunology. 2009;10(39):1-13.

62. Cho E, Lee J, Cho S. Systemic Contact Dermatitis from Propolis Ingestion. Ann Dermatol. 2011;23(1):85-8.

63. Teraki Y, Shiohara T. Propolis induced granulomatous contact dermatitis accompanied by marked lymphadenopathy. Br J Dermatol. 2001;144(6):1262-95.

64. Conti ME, Botrè F. Honeybees and their products as potential bioindicators of heavy metals contamination. Environ Monit Assess. 2001;69(3):267-82. 